\title{
Kinetics and Mechanism of Oxidation of Triethylene Glycol and Tetraethylene Glycol by Ditelluratoargentate (III) in Alkaline Medium
}

\author{
Jinhuan Shan and Caihong Yin \\ College of Chemistry and Environmental Science, Hebei University, Baoding 071002, China \\ Correspondence should be addressed to Jinhuan Shan; shanjinhuaner@yahoo.com.cn
}

Received 25 February 2012; Accepted 26 April 2012

Academic Editor: Nianjun Yang

Copyright (C) 2013 J. Shan and C. Yin. This is an open access article distributed under the Creative Commons Attribution License, which permits unrestricted use, distribution, and reproduction in any medium, provided the original work is properly cited.

\begin{abstract}
The kinetics of oxidation of triethylene glycol and tetraethylene glycol by ditelluratoargentate (III) (DTA) in alkaline liquids has been studied spectrophotometrically in the temperature range of $293.2 \mathrm{~K}-313.2 \mathrm{~K}$. The reaction rate showed first-order dependence in DTA and fractional order with respect to triethylene glycol or tetraethylene glycol. It was found that the pseudo-first-order rate constant $\left(k_{\text {obs }}\right)$ increased with an increase in concentration of $\mathrm{OH}^{-}$and a decrease in concentration of $\mathrm{H}_{4} \mathrm{TeO}_{6}{ }^{2-}$. There was a negative salt effect and no free radicals were detected. A plausible mechanism involving a two-electron transfer was proposed, and the rate equations derived from the mechanism explained all the experimental results and observations. The activation parameters along with the rate constants of the rate-determining step were calculated.
\end{abstract}

\section{Introduction}

Recently, many researchers from many countries are interested in the study of the highest oxidation state of transition metals which in a higher oxidation state generally can be stabilized by chelation with suitable polydentate ligands. Metal chelates, such as diperiodatoargentate (III) [1], ditelluratoargentate (III) [2], ditelluratocuprate (III) [3], and diperiodatonickelate (IV) [4], are good oxidants in a medium with an appropriate $\mathrm{pH}$. The oxidation of a number of organic compounds and metals in lower oxidation state by $\mathrm{Ag}(\mathrm{III})$ has also been performed [5,6]. The research is focus on the kinetics of oxidation of small molecules by DTA. In this paper, the mechanism of the oxidation of triethylene glycol and tetraethylene glycol by DTA is reported. Both of triethylene glycol and tetraethylene glycol which serve as thinners, solvent, and dispersant, are used in coatings, inks, printing, dyeing, pesticide, cellulose and acrylic acid industry, and so forth. In addition, they also can be used as fuel antifreeze, cleaning agents, the extractant, nonferrous metal dressing agent and organic synthetic materials, and so forth.

\section{Experimental}

2.1. Materials. All of the reagents used were AR grade. All of solutions were prepared with doubly distilled water. Solution of DTA was prepared and standardized by the method reported earlier [7]. Its UV spectrum was found to be consistent with that reported. The concentration of DTA was derived from its absorption at $\lambda=351 \mathrm{~nm}$. The solution of DTA was prepared with double-distilled water before using. The ionic strength $\mu$ was maintained by adding the solution of $\mathrm{KNO}_{3}$, and the $\mathrm{pH}$ of the reaction mixture was regulated with the solution of $\mathrm{KOH}$. The kinetic measurements were performed on a UV-Vis spectrophotometer (TU-1900, Beijing Puxi Inc., China), which had a cellholder kept at a constant temperature $\left( \pm 0.1^{\circ} \mathrm{C}\right)$ by circulating water from a thermostat (DC-2010, Baoding, China). None of the other species absorbed significantly at this wavelength.

2.2. Kinetics Measurements and Product Analysis. All kinetics measurements were carried out under pseudo-first-order conditions. A solution of $\mathrm{Ag}(\mathrm{III}), \mathrm{OH}^{-}$, and $\mathrm{H}_{4} \mathrm{TeO}_{6}{ }^{2-}$ with 


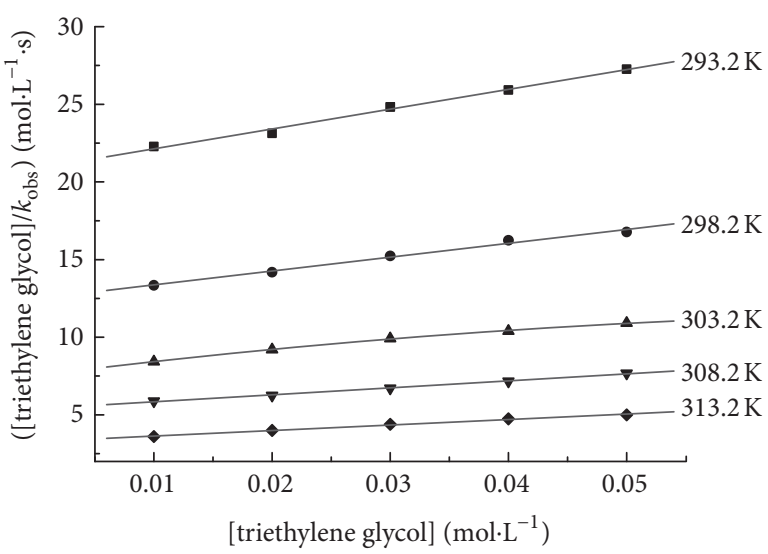

FIGURE 1: Plots of [triethylene glycol] $/ k_{\mathrm{obs}}$ versus [triethylene glycol $](r \geq 0.999)[\mathrm{Ag}(\mathrm{III})]=5.21 \times 10^{-4} \mathrm{~mol} \cdot \mathrm{L}^{-1},\left[\mathrm{OH}^{-}\right]=$ $1.00 \times 10^{-2} \mathrm{~mol} \cdot \mathrm{L}^{-1},\left[\mathrm{H}_{4} \mathrm{TeO}_{6}{ }^{2-}\right]=1.00 \times 10^{-3} \mathrm{~mol} \cdot \mathrm{L}^{-1}, \mu=3.80 \times$ $10^{-2} \mathrm{~mol} \cdot \mathrm{L}^{-1}$.

known concentrations was mixed with an excess of reductants. The complete fading of DTA color (reddish brown) marked the completion of the reaction. The product of oxidation was identified as ketone by its characteristic spot test [8].

\section{Results and Discussion}

3.1. Evaluation of Pseudo-First-Order Rate Constants. Under the conditions of [reductant $]_{0} \gg[\mathrm{Ag}(\mathrm{III})]_{0}$, the plots of $\ln \left(A_{t}-A_{\infty}\right)$ versus time were straight lines, indicating the reaction is first order with respect to $[\mathrm{Ag}(\mathrm{III})]$, where $A_{t}$ and $A_{\infty}$ are the absorbance at time $\mathrm{t}$ and at infinite time, respectively. The pseudo-first-order rate constants $k_{\text {obs }}$ were calculated by the method of least squares $(r \geq 0.999)$. The values of $k_{\text {obs }}$ were the average values of at least three independent experiments. The reproducibility was within $\pm 5 \%$.

3.2. Rate Dependence on the [Reductant]. At fixed concentration of $\mathrm{Ag}(\mathrm{III}), \mathrm{OH}^{-}, \mathrm{H}_{4} \mathrm{TeO}_{6}{ }^{2-}$, and ionic strength $\mu$, the values of $k_{\text {obs }}$ were determined at different temperatures. The plots of $\ln k_{\text {obs }}$ versus $\ln [$ reductant] were linear $(r \geq$ 0.999), and from the slope of such plots, the order with respect to reductant was found to be fractional. The plots of [reductant] $/ k_{\text {obs }}$ versus [reductant] were straight lines at different temperatures (Figures 1 and 2).

3.3. Rate Dependence on the $\left[\mathrm{OH}^{-}\right]$. At fixed concentrations of $\mathrm{Ag}(\mathrm{III}), \mathrm{H}_{4} \mathrm{TeO}_{6}{ }^{2-}$, reductant, ionic strength $\mu$, and temperature $(298.2 \mathrm{~K})$, the values of $k_{\text {obs }}$ increased with increasing concentration of $\mathrm{OH}^{-}$. The order with respect to $\left[\mathrm{OH}^{-}\right]$was fractional, and the plot of $1 / k_{\text {obs }}$ versus $1 /\left[\mathrm{OH}^{-}\right]$ was linear (Figure 3).

3.4. Rate Dependence on the $\left[\mathrm{H}_{4} \mathrm{TeO}_{6}{ }^{2-}\right]$. At constant [Ag(III)], [reductant], $\left[\mathrm{OH}^{-}\right], \mu$, and temperature $(298.2 \mathrm{~K})$,

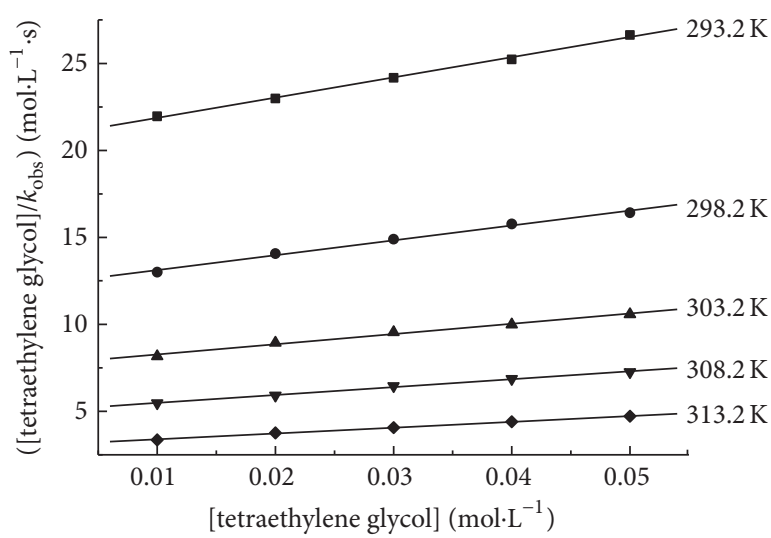

FIGURE 2: Plots of [tetraethylene glycol] $/ k_{\text {obs }}$ versus [tetraethylene glycol] $(r \geq 0.999)[\mathrm{Ag}(\mathrm{III})]=5.21 \times 10^{-4} \mathrm{~mol} \cdot \mathrm{L}^{-1},\left[\mathrm{OH}^{-}\right]=$ $1.00 \times 10^{-2} \mathrm{~mol} \cdot \mathrm{L}^{-1},\left[\mathrm{H}_{4} \mathrm{TeO}_{6}{ }^{2-}\right]=1.00 \times 10^{-3} \mathrm{~mol} \cdot \mathrm{L}^{-1}, \mu=3.80 \times$ $10^{-2} \mathrm{~mol} \cdot \mathrm{L}^{-1}$.

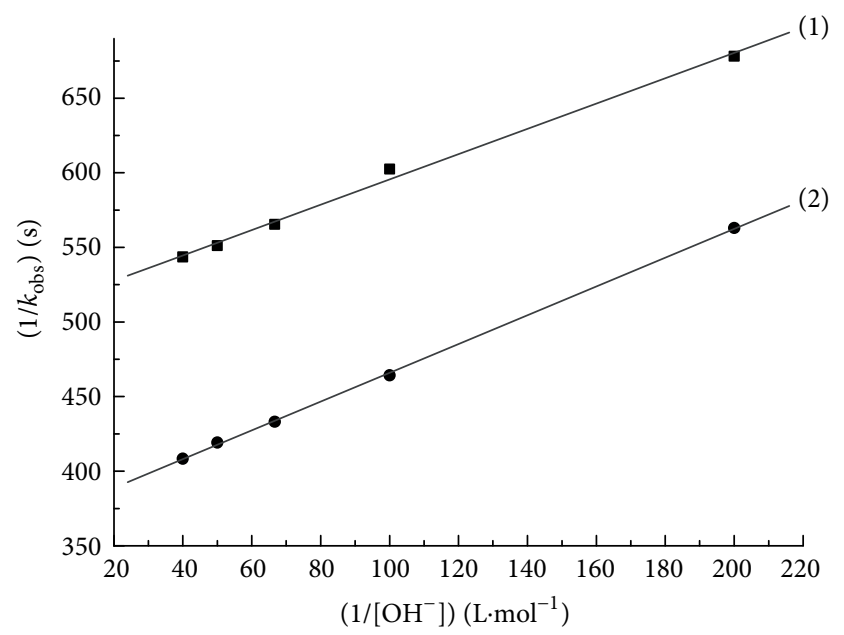

Figure 3: Plots of $1 / k_{\text {obs }}$ versus $1 /\left[\mathrm{OH}^{-}\right]$at $298.2 \mathrm{~K}(r \geq 0.999)$ $[\mathrm{Ag}(\mathrm{III})]=5.21 \times 10^{-4} \mathrm{~mol} \cdot \mathrm{L}^{-1},\left[\mathrm{H}_{4} \mathrm{TeO}_{6}{ }^{2-}\right]=1.00 \times 10^{-3} \mathrm{~mol} \cdot \mathrm{L}^{-1}, \mu=$ $\mu=3.80 \times 10^{-2} \mathrm{~mol} \cdot \mathrm{L}^{-1}$. (1) [Triethylene glycol] $=3.00 \times 10^{-2} \mathrm{~mol} \cdot \mathrm{L}^{-1}$. (2) $\left[\right.$ Tetraethylene glycol] $=3.00 \times 10^{-2} \mathrm{~mol} \cdot \mathrm{L}^{-1}$.

the experimental results indicated that $k_{\text {obs }}$ decreased while the $\left[\mathrm{H}_{4} \mathrm{TeO}_{6}{ }^{2-}\right]$ increased. The order with respect to $\mathrm{H}_{4} \mathrm{TeO}_{6}{ }^{2-}$ was derived to be an inverse fraction, which revealed that $\mathrm{H}_{4} \mathrm{TeO}_{6}{ }^{2-}$ was produced in equilibrium before the rate-determining step. A plot of $1 / k_{\text {obs }}$ versus $\left[\mathrm{H}_{4} \mathrm{TeO}_{6}{ }^{2-}\right]$ was a straight line (Figure 4).

3.5. Rate Dependence on the Ionic Strength. With other conditions fixed, the reaction rate was decreased by the addition of $\mathrm{KNO}_{3}$ solution (Table 1), which indicated there was negative salt effect which was consistent with the common regulation of the kinetics [9]. 
TABLE 1: Rate dependence on ionic strength $\mu$.

\begin{tabular}{lcccccc}
\hline & $10^{2} \mu / \mathrm{mol}^{-\mathrm{L}^{-1}}$ & 1.50 & 3.00 & 4.50 & 7.00 & 1.50 \\
\hline \multirow{2}{*}{$10^{3} \mathrm{k}_{\mathrm{obs}} / \mathrm{s}^{-1}$} & Triethylene glycol & 1.73 & 1.58 & 1.52 & 1.51 & 1.40 \\
& Tetraethylene glycol & 1.80 & 1.65 & 1.62 & 1.57 \\
\hline
\end{tabular}

$[\mathrm{Ag}(\mathrm{III})]=5.21 \times 10^{-4} \mathrm{~mol} \cdot \mathrm{L}^{-1},[$ reductant $]=3.00 \times 10^{-2} \mathrm{~mol} \cdot \mathrm{L}^{-1},\left[\mathrm{OH}^{-}\right]=1.00 \times 10^{-2} \mathrm{~mol} \cdot \mathrm{L}^{-1},\left[\mathrm{H}_{4} \mathrm{TeO}_{6}{ }^{2-}\right]=1.00 \times 10^{-3} \mathrm{~mol} \cdot \mathrm{L}^{-1}, T=298.2 \mathrm{~K}$.

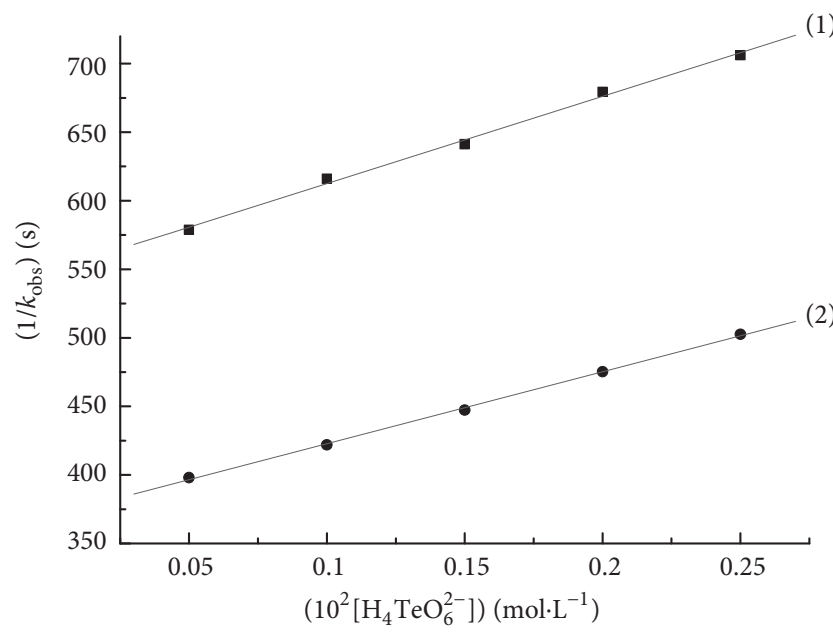

Figure 4: Plots of $1 / k_{\text {obs }}$ versus $10^{2}\left[\mathrm{H}_{4} \mathrm{TeO}_{6}{ }^{2-}\right]$ at $298.2 \mathrm{~K}(r \geq$ $0.999)[\mathrm{Ag}(\mathrm{III})]=5.21 \times 10^{-4} \mathrm{~mol} \cdot \mathrm{L}^{-1},\left[\mathrm{OH}^{-}\right]=1.00 \times 10^{-2} \mathrm{~mol} \cdot \mathrm{L}^{-1}$, $\mu=3.80 \times 10^{-2} \mathrm{~mol} \cdot \mathrm{L}^{-1},(1)\left[\right.$ triethylene glycol] $=3.00 \times 10^{-2} \mathrm{~mol} \cdot \mathrm{L}^{-1}$. (2) $\left[\right.$ Tetraethylene glycol] $=3.00 \times 10^{-2} \mathrm{~mol} \cdot \mathrm{L}^{-1}$.

3.6. Reaction Mechanism. In an alkaline medium, the electric dissociation equilibrium of telluric acid was given earlier $\left(\mathrm{pK}_{\mathrm{w}}=14\right)$ :

$$
\begin{gathered}
\mathrm{H}_{5} \mathrm{TeO}_{6}{ }^{-}+\mathrm{OH}^{-} \rightleftharpoons \mathrm{H}_{4} \mathrm{TeO}_{6}{ }^{2-}+\mathrm{H}_{2} \mathrm{O} \quad \lg \beta 1=3.049, \\
\mathrm{H}_{4} \mathrm{TeO}_{6}{ }^{-2}+\mathrm{OH}^{-} \rightleftharpoons \mathrm{H}_{3} \mathrm{TeO}_{6}{ }^{-3}+\mathrm{H}_{2} \mathrm{O} \quad \lg \beta 2=-1 .
\end{gathered}
$$

The distribution of all species of tellurate in aqueous alkaline solution can be calculated from (1) and (2). In the alkaline medium, $\left[\mathrm{OH}^{-}\right]=0.01 \mathrm{~mol} \cdot \mathrm{L}^{-1}$, the equation can be calculated: $\left[\mathrm{H}_{4} \mathrm{TeO}_{6}{ }^{2-}\right]:\left[\mathrm{H}_{5} \mathrm{TeO}_{6}{ }^{-}\right]:\left[\mathrm{H}_{3} \mathrm{TeO}_{6}{ }^{3-}\right]=1000: 89: 1$; in the concentration range of $\mathrm{OH}^{-}$used in this work, the $\mathrm{H}_{5} \mathrm{TeO}^{6-}$ and $\mathrm{H}_{3} \mathrm{TeO}_{6}{ }^{3-}$ species can be neglected and the main tellurate species is $\mathrm{H}_{4} \mathrm{TeO}_{6}{ }^{2-}$. According to the literature [10], the main DTA species is $\left[\mathrm{Ag}\left(\mathrm{H}_{4} \mathrm{TeO}_{6}\right)_{2}\right]^{-}$over the experimental concentration range of $\left[\mathrm{OH}^{-}\right]$.

According to the above experimental facts, the following reaction mechanism is proposed:

$$
\begin{aligned}
& {\left[\operatorname{Ag}\left(\mathrm{H}_{4} \mathrm{TeO}_{6}\right)_{2}\right]^{-}+\mathrm{OH}^{-}} \\
& \quad \stackrel{K_{1}}{\rightleftharpoons}\left[\mathrm{Ag}\left(\mathrm{H}_{3} \mathrm{TeO}_{6}\right)\right]+\mathrm{H}_{4} \mathrm{TeO}_{6}{ }^{2-}+\mathrm{H}_{2} \mathrm{O},
\end{aligned}
$$

$$
\begin{aligned}
& {\left[\mathrm{Ag}\left(\mathrm{H}_{3} \mathrm{TeO}_{6}\right)\right]+\mathrm{HOCH}_{2} \mathrm{RCH}_{2} \mathrm{OH}} \\
& \quad \stackrel{\mathrm{K}_{2}}{\rightleftharpoons}\left[\mathrm{Ag}\left(\mathrm{H}_{3} \mathrm{TeO}_{6}\right)\left(\mathrm{HOCH}_{2} \mathrm{RCH}_{2} \mathrm{OH}\right)\right] \\
& {\left[\mathrm{Ag}\left(\mathrm{H}_{3} \mathrm{TeO}_{6}\right)\left(\mathrm{HOCH}_{2} \mathrm{RCH}_{2} \mathrm{OH}\right)\right]} \\
& \underset{\text { slow }}{\stackrel{k}{\longrightarrow}} \mathrm{Ag}(\mathrm{I})+\mathrm{HOCH}_{2} \mathrm{RCHO} .
\end{aligned}
$$

Reactions (3) and (4) are dissociation and coordination equilibrium, the reaction rates of which are generally fast, reaction (5) is an electron-transfer reaction, the reaction rates of which are generally slow. Hence, reaction (5) is the ratedetermining step:

$$
\frac{-\mathrm{d}[\mathrm{Ag}(\mathrm{III})]_{t}}{\mathrm{~d} t}=k\left[\mathrm{Ag}\left(\mathrm{H}_{3} \mathrm{TeO}_{6}\right)\left(\mathrm{HOCH}_{2} \mathrm{RCH}_{2} \mathrm{OH}\right)\right] .
$$

$[\mathrm{Ag}(\mathrm{III})]_{t}$ stands for any form of $\mathrm{Ag}(\mathrm{III})$ complex which exists in the equilibrium and $\mathrm{R}^{\prime}$ stands for both of the reductants:

$$
\begin{aligned}
& \frac{-\mathrm{d}[\mathrm{Ag}(\mathrm{III})]_{t}}{\mathrm{~d} t} \\
& =\frac{k K_{1} K_{2}\left[\mathrm{R}^{\prime}\right]\left[\mathrm{OH}^{-}\right]}{K_{1} K_{2}\left[\mathrm{R}^{\prime}\right]\left[\mathrm{OH}^{-}\right]+K_{1}\left[\mathrm{OH}^{-}\right]+\left[\mathrm{H}_{4} \mathrm{TeO}_{6}{ }^{2-}\right]}[\mathrm{Ag}(\mathrm{III})]_{t} \\
& =k_{\mathrm{obs}}[\mathrm{Ag}(\mathrm{III})]_{t}, \\
& k_{\text {obs }}=\frac{k K_{1} K_{2}\left[\mathrm{R}^{\prime}\right]\left[\mathrm{OH}^{-}\right]}{K_{1} K_{2}\left[\mathrm{R}^{\prime}\right]\left[\mathrm{OH}^{-}\right]+K_{1}\left[\mathrm{OH}^{-}\right]+\left[\mathrm{H}_{4} \mathrm{TeO}_{6}{ }^{2-}\right]}
\end{aligned}
$$

Rearranging (8) leads to the following:

$$
\begin{gathered}
\frac{\left[\mathrm{R}^{\prime}\right]}{k_{\mathrm{obs}}}=\frac{\left[\mathrm{R}^{\prime}\right]}{k}+\frac{\left[\mathrm{H}_{4} \mathrm{TeO}_{6}{ }^{2-}\right]+K_{1}\left[\mathrm{OH}^{-}\right]}{k K_{1} K_{2}\left[\mathrm{OH}^{-}\right]}, \\
\frac{1}{k_{\mathrm{obs}}}=\frac{1+K_{2}\left[\mathrm{R}^{\prime}\right]}{k K_{2}\left[\mathrm{R}^{\prime}\right]}+\frac{\left[\mathrm{H}_{4} \mathrm{TeO}_{6}{ }^{2-}\right]}{k K_{1} K_{2}\left[\mathrm{R}^{\prime}\right]} \frac{1}{\left[\mathrm{OH}^{-}\right]} .
\end{gathered}
$$

From (9), the plots of $\left[\mathrm{R}^{\prime}\right] / k_{\text {obs }}$ versus $\left[\mathrm{R}^{\prime}\right]$ are straight lines, and the rate constants of the rate-determining step at different temperatures are obtained from the slope of the straight line. Equation (10) indicates that the plots of $1 / k_{\text {obs }}$ versus $1 /\left[\mathrm{OH}^{-}\right]$and $1 / k_{\mathrm{obs}}$ versus $\left[\mathrm{H}_{4} \mathrm{TeO}_{6}{ }^{2-}\right]$ are straight lines. Activation energy and the thermodynamic parameters are evaluated by the method given earlier (Table 2). 
TABLE 2: Rate constants $(k)$ and activation parameters of the rate-determining step $(T=298.2 \mathrm{~K})$.

\begin{tabular}{lccccc}
\hline & $T / K$ & 293.2 & 298.2 & 303.2 & 308.2 \\
\hline $10^{3} \mathrm{k} / \mathrm{s}^{-1}$ & Triethylene glycol & 7.84 & 11.21 & 16.27 & 20.85 \\
& Tetraethylene glycol & 8.61 & 11.71 & 16.98 & 22.02 \\
\hline \multirow{2}{*}{$\begin{array}{l}\text { Thermodynamic } \\
\text { activation } \\
\text { parameters }\end{array}$} & Triethylene glycol & & $\mathrm{Ea} /\left(\mathrm{kJ} \cdot \mathrm{mol}^{-1}\right)=48.64, \Delta \mathrm{H}^{\neq} /\left(\mathrm{kJ} \cdot \mathrm{mol}^{-1}\right)=46.16$, \\
& & & $\Delta \mathrm{S}^{\neq} /\left(\mathrm{J} \cdot \mathrm{K}^{-1} \cdot \mathrm{mol}^{-1}\right)=-127.51, T=298.2 \mathrm{~K}$ \\
& Tetraethylene glycol & & & $\mathrm{Ea} /\left(\mathrm{kJ} \cdot \mathrm{mol}^{-1}\right)=47.63, \Delta \mathrm{H}^{\neq} /\left(\mathrm{kJ} \cdot \mathrm{mol}^{-1}\right)=45.16$, \\
& & $\Delta \mathrm{S}^{\neq} /\left(\mathrm{J} \cdot \mathrm{K}^{-1} \cdot \mathrm{mol}^{-1}\right)=-130.34, T=298.2 \mathrm{~K}$
\end{tabular}

The plot of lnk versus $1 / T$ have following intercept (a), slope (b), and relative coefficient $(r)$.

Triethylene glycol: $a=15.13, b=-5850.17, r=0.997$. Tetraethylene glycol: $a=14.79, b=-5729.47, r=0.998$.

\section{Conclusion}

Based on the former discussion and results, we can know that the rate constants of the rate-determining step and the activation parameters for triethylene glycol and tetraethylene glycol are contiguous. Both of triethylene glycol and tetraethylene glycol form the same intermediate compounds with Ag(III), and the rate of tetraethylene glycol is a little quicker than that of triethylene glycol. The reason is that the electron-donating ability of tetraethylene glycol is larger than that of triethylene glycol. The transition complex formation between tetraethylene glycol and DTA is more stable than that of triethylene glycol.

\section{References}

[1] A. Kumar, Vaishali, and P. Ramamurthy, "Kinetics and mechanism of oxidation of ethylenediamine and related compounds by diperiodatoargentate (III) ion," International Journal of Chemical Kinetics, vol. 32, no. 5, pp. 286-293, 2000.

[2] T. R. Prasad, B. Sethuram, and T. N. Rao, "Oxidation of aliphatic amines by ditelluratoargentate(III)," Indian Journal of Chemistry, vol. 21, pp. 169-170, 1982.

[3] J. H. Shan, L. P. Wang, and H. W. Sun, "Kinetics and mechanism of oxidation of some hydroxy butyric acid salts by ditelluratocuprate(III) in alkaline medium," Turkish Journal of Chemistry, vol. 27, no. 2, pp. 265-272, 2003.

[4] J. H. Shan, H. Y. Wei, and L. Wang, "Kinetics and mechanism of oxidation of ethyleneglycol monobutylether by dihydroxydiperiodatonickelate(IV) complex in alkaline medium," Chemical Journal on Internet, vol. 3, no. 11, Article ID 03b055pe, p. $55,2001$.

[5] P. K. Jaisswal and K. L. Yadava, "Silver (III) as an oxidative titrant: determination of some sugars, carboxylic acids and inorganic ions," Talanta, vol. 17, no. 3, pp. 236-238, 1970.

[6] S. Chandra and K. L. Yadava, "Oxidation of some sugars with copper(III)," Talanta, vol. 15, no. 3, pp. 349-352, 1968.

[7] K. K. Gupta, B. K. Nandy, and S. Gupta, "Kinetics of oxidation of azide ion by bis(dihydrogentellurato)-cuprate(III) and -argentate(III) in alkaline media," Journal of the Chemical Society, Dalton Transactions, no. 7, pp. 1227-1232, 1995.

[8] F. Feigl, Spot Tests in Organic Anaiysis, Elsevier, New York, NY, USA, 1966.

[9] J. J. Jin, Kinetics Principle of Chemical Reaction in Liquid Phase, Science Technique Press, Shanghai, China, 1966.
[10] T. Raviprasad, B. Sethuram, and T. N. Rao, "Kinetics and mechanism of oxidation of lactic acid by dihydroxyditelluratoargentate (III) in alkaline medium," Indian Journal of Chemistry, vol. 18, pp. 40-42, 1979. 

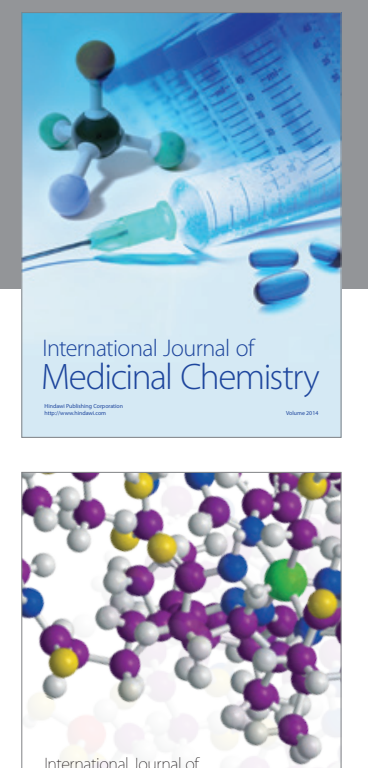

\section{Carbohydrate} Chemistry

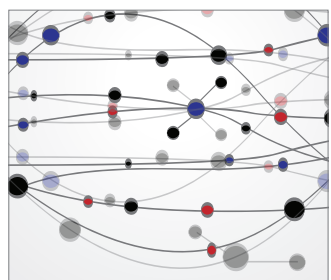

The Scientific World Journal
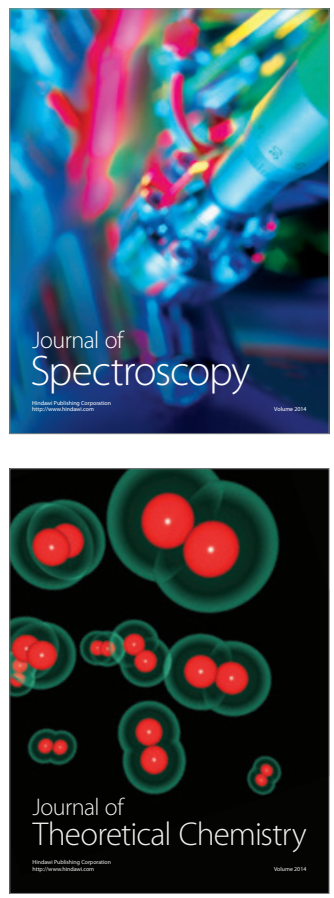
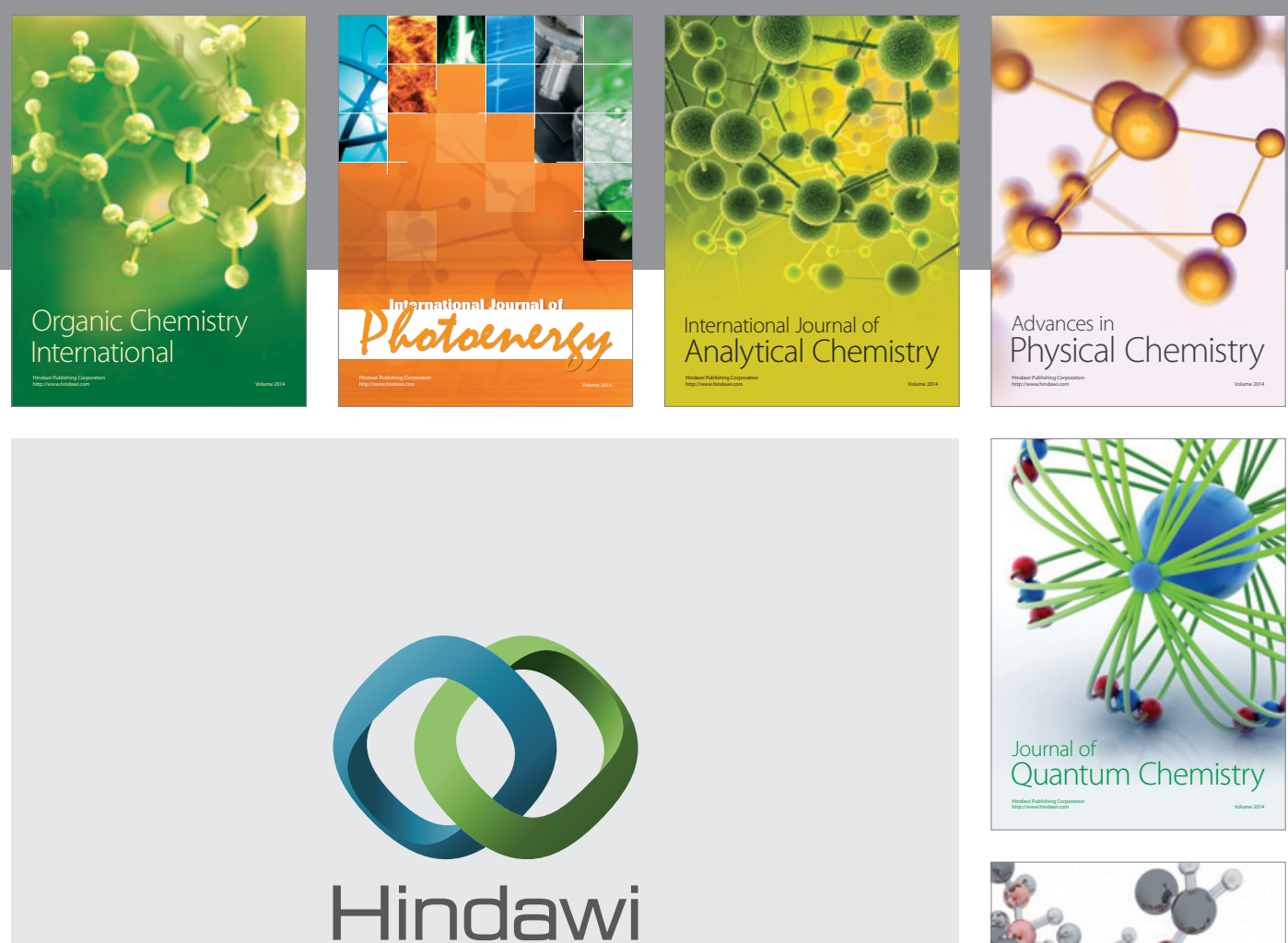

Submit your manuscripts at

http://www.hindawi.com

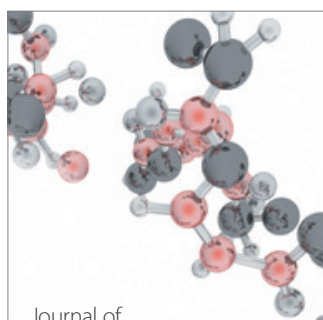

Analytical Methods

in Chemistry

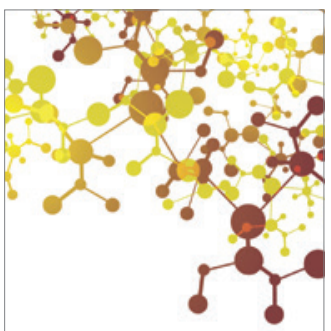

Journal of

Applied Chemistry

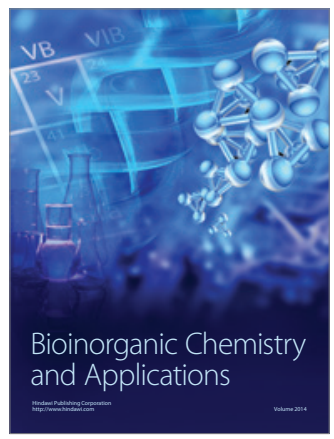

Inorganic Chemistry
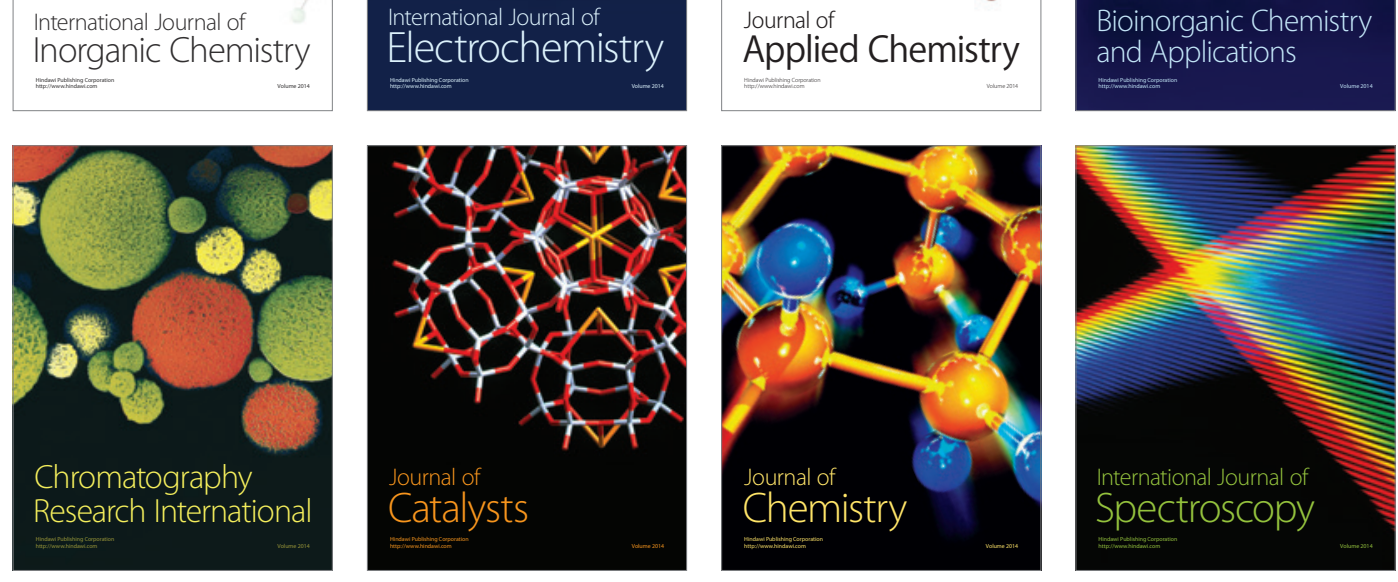